\title{
The Impact of Regulation on the Retail Prices in Fixed-Line Telephony across the European Union*
}

\author{
Lukasz Grzybowski ${ }^{\dagger}$
}

revised November 2006

\begin{abstract}
This paper estimates reduced-form models for incumbent prices in the fixed telecommunications industry using data for EU countries from 1998 to 2002. The regulation of fixed-line telephony has a significant impact on prices for residential consumers. Liberalization of the telecommunications industry decreased retail prices by about $8.2 \%$. The introduction of carrier pre-selection and number portability have a negative impact on price levels. Furthermore, a $1 \%$ decrease in termination charges on incumbent networks leads to a $0.17 \%$ decrease in retail prices.
\end{abstract}

Keywords: fixed-line telephony, regulatory policy, interconnection charges, reduced-form model. JEL Classification: L59, L96.

${ }^{*}$ I greatly acknowledge financial support from Volkswagen Stiftung and Munich Graduate School of Economics which made this research possible.

${ }^{\dagger}$ Departamento de Fundamentos del Analisis Economico, Universidad de Alicante, Campus de San Vicente, 03080 Alicante, Spain. E-mail: lukasz@merlin.fae.ua.es 


\section{Introduction}

Since the 1990s the European Union has been pursuing a common telecommunications regulatory policy aiming to establish a liberalized and harmonized pan-European telecommunications market, to stimulate economic growth, increase employment and the standard of living in the European Community. ${ }^{1}$ The initial regulation aimed to transform telecommunications monopolies into competitive industries. Since $1^{\text {st }}$ January 1998 telecommunications markets in the EU have been fully liberalized. ${ }^{2}$ In order to assess the status of regulatory obligations, the Commission has been publishing annual reports on the implementation of the telecommunications regulatory package. The effects of regulation are evaluated using a range of economic indicators and in particular by comparing retail prices. As stated by the Commission in these reports, there is continuous improvement in the quality of services and corresponding decreases in prices.

The evaluation of regulation in fixed-line industry in the EU has so far been based on descriptive statistics, as presented in the annual reports published by the Commission. An exception to this is the recent study by Edwards and Waverman (2006) which uses regression analysis to explain interconnection charges in the European Union. This study also uses a simple econometric analysis to examine whether observable changes in prices of incumbents in the EU may be attributed to regulatory policy. It suggests looking at the differences in timing, at which regulation of fixed-line services was introduced across the EU and to estimate whether these differences explain the variation in retail prices. Such analysis should be of interest for policy makers by indicating whether and to what extend regulation has an impact on retail prices.

In the panel estimation which uses data on the EU countries from 1998 to 2002, retail prices of incumbent operators are regressed on regulatory variables, cost determinants and economic variables. Liberalization of fixed-line telephony and regulation, such as, implementation of carrier pre-selection (CPS) and number portability had a negative impact on residential prices. In the regression of the usage basket, regulation decreased average price levels across the EU

\footnotetext{
${ }^{1}$ Source: European Commission (1997c)

${ }^{2}$ Full liberalization was delayed in Portugal and Greece until 2000 and 2001, respectively. There were also delays of a few months in Ireland, Luxembourg and Spain.
} 
between the years 1998-2002 by about $8.2 \%$. Furthermore, a $1 \%$ decrease in termination charges on the incumbent network led to a $0.17 \%$ decrease in the cost of the basket. Differences in price levels are also explained by cost factors. Next, local and national call prices at peak and offpeak times are regressed on the interconnection charges and regulatory variables. The estimation results suggest that a $1 \%$ decrease in single transit interconnection charges on incumbent network led to a $0.31 \%$ decrease in incumbent national prices at peak time, as calculated for the average prices in the EU in 2002. Local interconnection charges seem to have no significant impact on incumbent retail prices for local calls. These results may indicate that incumbent operators are able to retain significant market power. Decreases in competitors' marginal costs make the incumbent decrease retail prices at a much lower rate.

The next section briefly reviews related literature. Section 3 presents main issues in the regulation of fixed-line telephony. Section 4 describes the data, empirical model and discusses the estimation results. The final section concludes.

\section{Literature Review}

There is a large body of studies analyzing the impact of telecommunications reforms, such as licensing, independent regulation, privatization, etc. on diffusion, efficiency and investments in the telecommunications industry. The studies on telecommunications reforms are usually very similar in their methodological approach. They use annual panel and cross-section data and estimate reduced form linear regressions or logistic diffusion models. Commonly used data sources are: the International Telecommunications Union (ITU), the OECD, the World Bank and the Eurostat. For instance, Ros (2003) and Berg and Gutierrez (2000) analyze determinants of the demand for fixed telephony in the Latin American countries using economic, institutional and regulatory variables. Ros (2003) finds that the presence of an independent regulator has a positive impact on fixed-line penetration. Privatization of the incumbent operator also has a positive influence on subscriptions. In another panel analysis of African and Latin American countries, Wallsten (2001) finds that the privatization of the incumbent operator is beneficial 
only in the presence of an independent regulator. Wallsten (2003) uses data on telecommunications industry worldwide to analyze whether the sequence of reforms matters. He finds that establishing a regulatory authority before privatizing the telecommunications incumbent is correlated with increased fixed-line penetration, telecom investments and subscriptions to mobile telephony. $\mathrm{Li}$ and $\mathrm{Xu}$ (2000) use panel data to examine the impact of privatization and competition on fixed-line subscriptions, labor and factor productivity in the telecommunications industry worldwide. Fink et al (2002) use panel data for 86 developing countries to analyze the impact of policy reform on fixed-line telecommunications. This list of related studies is far from exhaustive. However, to the best of my knowledge, studies which use prices as dependent variables are rather scarce. For instance, Boylaud and Nicoletti (2000) use factor analysis and panel data estimation to analyze the effects of entry, liberalization and privatization on productivity, prices and the quality of services in long-distance and mobile telephony across a few OECD countries. Bauer (2003) analyzes dependence between retail prices and license fees in mobile telephony for a cross-section of 18 OECD countries. As dependent variables, he uses prices of residential and business mobile baskets developed by Teligen for the OECD. He finds no empirical evidence that license fees influence retail prices.

Interestingly, there are almost no empirical studies which focus specifically on the regulatory reforms in telecommunications in EU countries. Gruber and Verboven (2001) analyze the impact of regulation on the diffusion of mobile services across the EU till 1998. Their study indicates the importance of government regulation and technological progress for technology diffusion. In particular, the diffusion of mobile services is augmented by market competition in terms of at least two competitors on the market. Grzybowski (2005) analyzes regulation in mobile telephony in the EU for the years 1998-2002 and finds that prices and subscriptions are significantly influenced by regulatory policy. Liberalization of fixed telephone lines has a positive impact on competition in mobile telephony as does the introduction of number portability for mobiles. In a recent study on fixed-line telephony, Edwards and Waverman (2006) examine the effects of public ownership and regulatory agency independence on interconnection charges in the EU. 
They find that public ownership of the incumbent affects interconnection rates positively. The presence of institutional features enhancing regulatory independence from the government mitigates this effect. As in this study, they use data from annual reports on the implementation of the telecommunications regulatory package published by the Commission.

This paper differs from the above-mentioned studies as it estimates a reduced form model, in which fixed-line prices of EU incumbents are explained by regulatory variables and cost determinants. The findings are similar to the study by Grzybowski (2005). Liberalization of telecommunications industry has a negative impact on retail prices in both mobile and fixed-line telephony.

\section{Regulation of Fixed-Line Telecommunications}

This section presents the main regulatory measures which could influence incumbents' retail prices in the fixed-line telephony. As in previous literature, the impact of regulation is measured by creating dummy variables, which take the value of one when the regulatory measure may be perceived as being implemented in a particular country. However, creating regulatory variables of this sort is arguable because the regulation, such as, tariff rebalancing, unbundling local loops or introducing number portability represents a process which may take years. It is difficult to confirm exactly when certain regulations have been implemented and when effects on prices can be seen. At least, compared to studies on countries from different regions around the world, there is a common EU regulatory policy and reports by the Commission publish comparable information as regards regulation. The effect of some regulatory measures cannot be identified at all due to the lack of variation across Member States in the time period considered.

The independence of National Regulatory Authorities (NRAs) is an essential requirement for regulatory reforms in the telecommunications industry. The NRAs must be structurally separated and act independently from the Ministry to which they report. Many of the abovementioned studies indicate that the independence of the regulator has an impact on the development of the telecommunications industry, see for example Ros (2003) and Wallsten (2001). The 
guidelines for the role of independent NRAs in the EU are set out in the EC Directives 97/33/EC and 98/33/EC. The NRAs must be given a full range of power to encompass bottlenecks and scarce resources, such as issues related to licensing, interconnection and special access, universal services and consumer protection, tariffs and accounting systems, numbering, rights of way, and local access competition. ${ }^{3}$

By 1998, all Member States established separate regulatory authorities. According to the 1998 report by the European Commission, the NRAs in all Member States, except Belgium, were legally independent from the Ministry. However, there were still concerns in some countries as to whether the control of the incumbent and regulatory functions were sufficiently separated. ${ }^{4}$ In further reports, the Commission noted that the actions taken by many regulators showed independence. However, there were still concerns regarding the functioning of certain regulators, lack of proactivity and powers. ${ }^{5}$ Independence of NRAs is critical for the issue of exogeneity of regulatory variables. Given that there is a common regulation for all Member States, whose implementation has been monitored by the Commission and according to which all all Member States must obey certain deadlines, it could be considered as exogenous. Thus, a simple OLS estimation should be consistent. Nevertheless, the instrumental variables method is used to test for the exogeneity of regulation.

The Commission acknowledges that cost-based interconnection charges are the best policy option to promote a competitive telecommunications industry. According to some estimates termination charges may represent up to $40 \%$ of the marginal costs involved in fixed-line services. ${ }^{6}$ Since liberalization in 1998, the Commission and the NRAs pay particular attention to the regulation and monitoring of interconnection charges. ${ }^{7}$ In general, interconnection charges should be set at a level which promotes productivity and encourages entry by efficient competi-

\footnotetext{
${ }^{3}$ Source: www.analysys.com

${ }^{4}$ Source: European Commission (1998)

${ }^{5}$ The ITU stated in its survey on telecommunications reform that the NRAs in the EU appear to have sufficient independence. Source: ITU (2002)

${ }^{6}$ Source: European Commission (1997a)

${ }^{7}$ Source: European Commission (1997c)
} 
tors. Consequently, Member States were required to implement interconnection prices based on forward-looking long run average incremental cost (FL-LRAIC). ${ }^{8}$ Until the interconnection charges based on FL-LRAIC are in place, the Commission recommended NRAs to use the international comparison of interconnection charges. The use of the best-practice benchmarks was supposed to help NRAs to evaluate the relation of interconnection charges to the costs. ${ }^{9}$ In early 2002, the Commission abandoned this policy stating that the cost-based interconnection charges have been implemented in all Member States. Nevertheless, the interpretation of "cost-based" as well as FL-LRAIC seems to differ among EU regulators. There are significant differences in the cost base and cost standard adopted in particular countries.

One of the main powers of the NRAs is the ability to notify operators as having significant market power (SMP) in certain telecommunications markets. According to the definition provided in the EC Directive $97 / 33$, operators with share of over $25 \%$ should be designated as an SMP. ${ }^{10}$ An SMP operator in the interconnection market must set transparent, nondiscriminatory and cost-based interconnection charges and must implement accounting separation for interconnection services. ${ }^{11}$ Since liberalization in 1998 incumbent operators in all Member States have been designated as having an SMP in the interconnection market. Thus, an SMP designation cannot be identified as the determinant of incumbents' retail prices in the time period considered.

\footnotetext{
${ }^{8}$ Interconnection Directive 97/33/EC (Recital 10): "charges for interconnection based on a price level closely linked to the long-run incremental cost for providing access to interconnection are appropriate for encouraging the rapid development of an open and competitive market."

${ }^{9}$ The Commission regularly publishes 'best current practice' for call termination on a fixed network for peak rates for calls of 3 minutes duration. There are three interconnection charges depending on the extent to which the entrant wishes to utilize the incumbent network - local, single transit and double transit interconnection. Local interconnection is used when an entrant hands over calls to the incumbent PTO at the local exchange nearest the party being called. Single transit interconnection is used to terminate a call anywhere within a metropolitan area. Double transit interconnection allows an entrant with a single point of presence in the incumbent PTO network to terminate a call anywhere on that network.

${ }^{10}$ Source: European Commission (1997b)

${ }^{11}$ Source: www.analysys.com
} 
A pre-requisite for competition in all segments of fixed-line telephony is tariff rebalancing. In the state monopoly local, residential and rural services were typically subsidized by international, long-distance and business services. In the competitive industry unbalanced prices are not sustainable and cross-subsidies must be abolished. Thus, tariff rebalancing aims to relate service prices to their costs as set out in the Commission's guidelines for cost orientation and adjustment of pricing structures. ${ }^{12}$ Tariff rebalancing results in lower prices for international and longdistance calls and generally increases charges for local calls, basic connection and rental. Thus, the impact of tariff rebalancing on the total cost of using fixed-line service may be ambiguous. According to the recent report by the Commission on the implementation of regulatory package, there is a noticeable increase in the EU average monthly rentals and in the price of local calls over the period 1997 to 2000. At the same time, the average price for long-distance and international calls has declined. The Commission stated that such price changes imply that some degree of tariff rebalancing has taken place in all Member States. In fact, tariff rebalancing should have been completed before 1st January 1998, but according to the Commission, this has not happened in most Member States. Measuring the effect of tariff rebalancing empirically is difficult because it is a process which may last for years. Moreover, as mentioned above, the NRAs use different cost methodologies for calculating the cost of interconnection. Hence, the assessment whether cost orientation requirement is satisfied may vary across countries. For these reasons tariff rebalancing cannot not be addressed in the empirical analysis.

An important regulatory issue which should raise competition is number portability, i.e. the ability of a consumer to retain the same telephone number when changing from one operator to another. The introduction of number portability should lower consumer switching costs and reduce prices. According to the EC Directive 98/61, NRAs must ensure that end users of fixed telephony are offered operator number portability for geographic numbers at a specific location and for non-geographic numbers at any location. The portability of fixed numbers had to be introduced in all Member States by January 2000, except those with a deferment. ${ }^{13}$

\footnotetext{
${ }^{12}$ Source: European Commission (1992)

${ }^{13}$ Source: European Commission (2002)
} 
The implementation of number portability is technically difficult and costly which makes the allocation of costs an important regulatory issue as well.

The other way of reducing switching costs is by allowing consumers to access other networks without being directly connected to them. Consumers have the possibility of using an alternative provider by dialling a call-by-call prefix (carrier selection) or by choosing to route all calls by default to the network of an alternative operator (carrier pre-selection). According to the EC Directive 98/61, the NRAs were required to ensure that, by 1st January 2000 fixed network operators with an SMP enabled their subscribers to obtain access to the services of other interconnected service providers by means of CS and CPS. Again, a few countries obtained a deferral for this date. According to the recent report on the implementation of the telecommunications regulatory package, CS and CPS are key driving forces of competition in the telecommunications market. CS/CPS penetration could be estimated at about $25 \%$ of all subscribers in the European Union for long-distance and international calls and $13 \%$ for local calls in 2004 . The carrier selection procedures differ from country to country but the general effect on competition should be the same, that is, an increase in the number of alternative operators and a decrease in retail prices of incumbents. However, empirical evidence on their impact on retail prices is still lacking. ${ }^{14}$

Furthermore, the incumbent operator is required to unbundle local loop (LLU) and to provide access to its copper lines at a rate which ensures recovery of costs and promotes competition. Unbundling should increase competition in local access but, in the long-run, the LLU reduces the incentives for the entry of facility-based competitors which may have a negative impact on competition. According to the Commission the implementation of LLU is an area in which the lack of proactivity and/or powers of NRAs has been observed in almost all Member States. The Commission stated that progress in the development of competition in local access is not satisfactory and that the number of fully unbundled lines represents a small percentage of the

\footnotetext{
${ }^{14}$ In almost all countries the implementation of CS and CPS was coordinated but the Commission usually refers to CPS in its reports. Thus, throughout the study I refer to CS/CPS as CPS.
} 
total access lines in Europe. ${ }^{15}$ In this study, a potential impact of LLU on prices is measured using a dummy variable which identifies the moment when unbundled access was legally enforced in particular Member States. Fully unbundled access is currently legally available in all old EU states but there are some differences as to when it was brought into force. Obviously, it may be difficult to measure the impact of LLU on retail prices in such a simple way suggested in this study. Incumbents unbundle their lines sequentially on certain geographic areas and other issues matter, such as prices for the local loop. There are great differences in prices for the local loop across Member States. ${ }^{16}$

Finally, most countries require price cap regulation and NRAs' approvals of end-user prices for voice telephony to induce competition and pursue public interest needs. For instance, according to the report by the Commission in 2003, price caps were in use in Belgium, Germany, Spain, Ireland, Italy, the Netherlands, Portugal and the UK. The remaining countries required different type of regulation or allowed prices to be freely set by the operators. In Denmark, a price ceiling was only applied for subscription and call setup, whilst the earlier price cap regulation was lifted as regards to the per minute charge. In France, prior approval from the Ministry (following the opinion of ART) in accordance with the open network provision (ONP) conditions was required. In Greece, NRA approval was required and Austrian NRA demanded ex ante approval under ONP conditions. Finally, tariffs were freely set by operators in Luxembourg, Finland and Sweden, but had to be cost orientated. ${ }^{17}$ Again, given that each country has a specific combination of price regulations, it is difficult represent it by a variable which could be used in an econometric model.

\footnotetext{
${ }^{15}$ Source: European Commission (2002)

${ }^{16}$ Unfortunately, there is no data available on the number of unbundled lines for the whole time period of this study. However, even if it was available, such information still may not help to identify the impact of LLU on prices because the area in which lines are unbundled plays an important role. For instance, unbundled lines in the capital have different impact on the competition than unbundled lines in a provincial town, where few entrants wish to provide services.

${ }^{17}$ Source: European Commission (2003)
} 


\section{The Empirical Analysis}

\subsection{The Data}

The main sources of data used in this study are publicly available reports by the Commission on the implementation of telecommunications regulatory package and the database on worldwide telecommunications industry provided by the ITU. Data on incumbents' prices is accessible in the reports provided by the consultancy agency Teligen for the Commission. Pricing data is available for old EU countries for the years between 1998 and 2002. The explanatory variables include some of the regulatory variables discussed in the former section, country characteristics and cost factors.

\subsubsection{Prices}

There are five regressions presented in this analysis, in which the dependent variables are respectively: monthly cost of incumbent usage basket in fixed telephony, local and national prices for calls of a duration of 5 minutes at peak and off-peak times.

A typical fixed-line tariff consists of several components, such as connection charge, monthly rental fee and call charges differentiated according to peak and off-peak timing and in respect to local, national, international and mobile destinations. A common approach used for international price comparisons is the OECD basket methodology, which calculates the annual cost of using telecommunications services for a typical business or residential telephone consumer. This study uses the OECD guidelines and publicly available reports on incumbents' prices for telecommunications services in the EU to calculate the cost of using a fixed-line for a representative residential consumer. ${ }^{18}$

Following the OECD basket definition, only the most important pricing elements are used in the calculation, such as: connection fee, monthly rental fee and peak, off-peak call charges to local, national, international and mobile destinations with appropriate weights. The residential consumer is assumed to use fixed-line services provided by the incumbent operator and makes

\footnotetext{
${ }^{18}$ Source: OECD (2000)
} 
900 local and 300 national calls a year of a duration of 5 minutes, out of which $64 \%$ are off-peak calls. Furthermore, he makes 72 international calls lasting 5 minutes and 120 calls to mobiles lasting 3 minutes, out of which $75 \%$ are off-peak calls. Hence, the monthly cost of fixed-line service consists of the total annual cost of calls divided by 12 months plus monthly rental fee plus network connection fee divided by 36 months. The price of the residential basket includes VAT and is listed in \$US PPP which makes it comparable over time and across countries and independent on inflation and differences in purchasing power. ${ }^{19}$

\subsubsection{Explanatory Variables}

Price may be divided into two components: marginal cost and margin. Differences in price levels across EU countries must result from varying determinants of any of these components. There may be some differences in cost factors. For example, the cost of labor and capital could vary across countries and over time. Margins may vary due to differences in implementation of regulatory measures, for instance. Marginal costs and margins could be influenced by demand side factors. In the reduced-form estimation, incumbent prices are regressed on exogenous explanatory variables which appear on both the demand and supply side.

Following the discussion in the previous subsection, there are some regulatory measures which may influence fixed-line prices: a dummy for the introduction of number portability in fixed-line networks (Portab), a dummy for the implementation of carrier pre-selection for national calls (CPS), a dummy for enforcing the unbundling of local loops (ULL) and a dummy for the liberalization of the telecommunications market (Libera). All variables are expected to have a negative impact on prices. The implementation of number portability and CPS decrease consumer switching costs, whilst the ULL should stimulate competition by decreasing entry barriers. The regulatory variables are negatively correlated with the price index but highly correlated with each other, as reported in Table (4). The implementation of regulatory measures in particular countries was coordinated and their separated impact on prices may

\footnotetext{
${ }^{19}$ The tariffs are from January of each year, with the exception of the years 2001 and 2002, for which the tariff is taken from December of the previous year, under assumption that it does not differ much from January's tariff.
} 
not be identifiable. In particular, carrier pre-selection and number portability were introduced almost at the same time, as presented in Table (2). Therefore, it may be reasonable to interpret the decrease in prices as a joint effect of regulation. ${ }^{20}$

\section{[Table 2]}

The other explanatory variables are determinants of the marginal cost of providing fixed-line services. The average hourly labor compensation cost in manufacturing in \$US PPP is used as a proxy for the cost of labor in the telecommunications industry (Labor) and the yield on the 10-year government bonds is the proxy for the cost of capital (Bond).$^{21}$ There may be some technological innovations on the supply side resulting in lower marginal costs and prices which are approximated in the estimation by time trend (Time). Another variable which may influence demand positively is income, with the consequent negative sign in the supply side regression. This is represented by GDP per capita in \$US PPP as a logarithm (GDP).

\section{[Table 1]}

Regulation may also lead to lower marginal costs for providing fixed-line services. The obligation imposed on SMP-designated firms to set cost-orientated interconnection charges should decrease the marginal costs of competitors. As already mentioned, such effect cannot be identified in this study as incumbent operators in all Member States have been designated with an SMP since 1998. However, since SMP operators are obliged to publish termination charges, they can be used as a proxy for interconnection regulation (Access).

\footnotetext{
${ }^{20}$ As mentioned in the former section, retail prices in some countries are directly regulated and depend on the type of price caps enforced. Also tariff rebalancing determines prices. Unfortunately, the effect of these measures cannot be identified within this simple framework.

${ }^{21}$ Grzybowski (2005) finds these variables to be significant cost factors in mobile telephony. Population density and urbanization may also determine the cost of providing fixed-line services. However, these variables turned out to be insignificant in pricing regressions. Similarly, Edwards and Leonard (2006) argue that population density does not determine interconnection charges.
} 


\subsection{The Empirical Model}

A following usage basket pricing equation is estimated:

$$
p_{j t}=R_{j t} \alpha+X_{j t} \beta+M C_{j t} \gamma+D_{j} \delta+\epsilon_{j t}
$$

where $j=1, \ldots, J$ is the country subscript, $t=1, \ldots, T$ is the time subscript and $p_{j t}$ is the monthly basket price for fixed-line services. On the right-hand side $R_{j t}=\left[\operatorname{Portab}_{j t}, C P S_{j t}\right.$, $U L L_{j t}, L_{i b e r a}{ }_{j t}$, Access $\left._{j t}\right]$ represents the set of regulatory variables, $X_{j t}=\left[G D P_{j t}\right]$ is the only non-regulatory variable and $M C_{j t}=\left[\right.$ Labor $_{j t}$, Bond ${ }_{j t}$, Time $\left.t\right]$ are cost factors including time trend. The term $\epsilon_{j t}$ represents unobservable demand and supply shocks which are assumed to be normally distributed and mean independent with the explanatory variables. Finally $D_{j}$ are country dummies. Alternatively, a random effects specification may be considered, which assumes that the error term consists of two components: the fixed country-specific component and a commonly distributed shock across all observations. For consistency of the estimates both unobserved components must be uncorrelated with the explanatory variables.

Apart from basket regression incumbent local and national prices for 5 minute calls at peak and off-peak times are regressed on regulatory variables $R_{j t}$. Basket and local prices are regressed on local interconnection charges and national prices on single transit interconnection. Both retail prices and interconnection charges are set by the incumbent. Thus, the interconnection charges may be endogenous which could cause a bias in the simple OLS estimation. An argument for OLS estimation is that both interconnection charges and retail prices are regulated by the NRAs and due to this regulation there may be some delay in the response of interconnection charges to demand and cost shocks. Moreover, the regulation results in decreasing interconnection charges.

An instrumental variables estimation method (two-stage least squares) is used to test for the exogeneity of interconnection charges and regulation. The set of instruments is selected from exogenous variables in the model and includes a measure of urbanization as additional variable: $Z_{t s}=\left[G D P_{t s}\right.$, Laborts $_{t s}$, Bond $_{t s}$, Timets Urban $_{t s}$, Libera $\left._{t s}, D_{1}, \ldots D_{14}\right]$, that is respectively: GDP per capita in \$US PPP as a logarithm, cost of labor, cost of capital, time trend, urbanization, liberalization dummy and country dummies. The instruments cannot be corre- 
lated with the unobservable demand and cost shocks and should be highly correlated with the endogenous variable, that is, interconnection charges and regulation. Cost factors, time trend and urbanization should be correlated with the interconnection charges. Liberalization may be considered as exogenous because it was announced and prepared for many years before January 1998 and was coordinated by the Commission. There is some variation in liberalization dates because a few countries were granted deferment. Liberalization is highly correlated with other regulatory variables, as presented in Table 4.

\subsection{Results}

The estimation results indicate that fixed-line service prices are determined by regulation and cost factors. In the fixed effects estimation a few listed explanatory variables have a significant impact on incumbent prices. These variables explain $94 \%$ of price variation (see specification II in Table 5). The hypothesis of insignificant fixed effects can be rejected with F-value at 27.49. Moreover, the Hausman test cannot reject the null hypothesis of exogeneity of interconnection and regulation (see 2SLS in Table 5). Hence, the OLS estimates should be unbiased. The fit for the random effects specification is worse at $R^{2}=0.70$ (see specification II in Table 6 ) and the Hausman test rejects the null hypothesis of random individual effects with an m-value equal to 8.89 .

The regulatory policy has a significant negative impact on incumbents' retail prices. In the fixed effects estimation the liberalization of the telecommunications industry lowered the average price levels across the EU by -7.40 SUS PPP, which implies an average decrease of approximately $8.2 \%$. The random effects specification suggests a problem with the collinearity of regulatory variables. In specification II in Table 6, when number portability is excluded, both liberalization and carrier pre-selection are significant. In specification III in Table 6, when CPS is excluded, liberalization and number portability are significant. The dummy for enforcing the unbundling of local loops on a country's territory is insignificant in both fixed and random effects regression. This could be due to a high correlation of the regulatory variables with each other or a failure 
to identify the effect by a simple dummy variable. Therefore, it may be reasonable to interpret the decrease in prices as a joint effect of regulation.

Finally, differences in price levels are also explained by cost factors. The marginal cost of providing fixed-line services seems to depend on the cost of capital and cost of labor (see Table 5). Time trend and GDP per capita are not significant. However, GDP per capita is significant in random effects specification. Thus, its insignificance in fixed effects estimation may be due to the small time variation of this variable.

Country dummies themselves explain a vast part of price variation. ${ }^{22}$. This may be due to differences in marginal costs and/or in the level of competition across the EU countries. Firstly, there could be significant differences in the cost of providing fixed-line services. For instance, the size of the country and population concentration may play a role due to universal service obligations but cannot be identified due to lack of variation. Incumbents could also differ in efficiency. Country dummies may include information about differences in market conduct and markups charged by the incumbents. The profitability of incumbents could also depend on regulation, which is not identifiable in this analysis, such as the price cap regulation. All these factors may potentially show up in the estimates of country dummies. Therefore, country dummies can be exclusively interpreted as differences in cross-country price levels. It cannot be determined whether these differences are due to differences in costs or markups. Only if the cost of capital and labor completely controlled for differences in marginal costs across Member States, country dummies could be interpreted as the index of competitiveness. Luxembourg has the lowest country dummy value followed by Sweden, the Netherlands, Denmark, Finland, Germany, Belgium and France. Ireland, Italy and Austria are at the same level as the UK because their dummies are insignificant (all country dummies are interpreted in respect to the dummy for the UK, noted as intercept). Finally, Portugal has the highest dummy value followed by Greece and Spain. In fact, such a grouping of countries roughly corresponds to a grouping in respect to the level of development of the telecommunications industry. Potentially, it may

\footnotetext{
${ }^{22} R^{2}=0.78$ in the regression of prices on country dummies only
} 
suggests that South-European countries are less competitive than Scandinavian countries.

Using regulatory variables estimates, the monetary loss involved in deferring the implementation of regulation can be calculated. For instance, the estimated revenue for public voice telephony in 1998 in Greece accounted for 2.3 billion Euros. ${ }^{23}$ Even for constant demand, it represents a per annum loss of approximately 0.19 billion Euros. The loss for other Member States which postponed liberalization and other regulations in 1998 amounts to approximately 0.16 billion Euros in case of Portugal (revenue of 2 billion Euros), 0.11 billion Euros for Ireland (revenue of 1.4 billion Euros) and 0.60 billion Euros for Spain (revenue of 7.3 billion Euros).

Table (7) presents pricing regressions for local and national 5 minute calls at peak and offpeak times. OLS estimates are reported only because the Hausman test cannot reject again the null hypothesis of exogeneity of interconnection and regulation. Hence, the OLS estimates should be unbiased.

There is not much variation in peak local prices over time and the cross-country variation is explained by country dummies with R-squared equal to $92 \%$. There is more time variation in prices for off-peak local calls and national peak and off-peak calls. R-squared in these regression is much lower at $48 \%, 82 \%$ and $80 \%$, respectively. Liberalization has a negative impact on peak and off-peak national call prices but no effect on local prices. Number portability significantly decreases local prices but has no effect on national prices. Again LLU is insignificant in all four regressions. Interconnection charges are significant in the regression of national prices at peak time. Its estimate implies that a $1 \%$ decrease in single transit charges leads to a $0.31 \%$ decrease in incumbent national peak prices, as calculated for the average prices in the EU in 2002 . In the remaining regressions interconnection turns out to be insignificant. These results are important from a policy perspective suggesting that regulation of interconnection charges is not as effective as expected. Decreases in competitors' marginal costs make the incumbent decrease retail prices at a much lower rate. It may indicate that incumbent operators are able to retain significant market power.

\footnotetext{
${ }^{23}$ Carrier service revenues for local, long distance and international voice telephony services for residential and business users. Source: European Commission (1998)
} 


\section{Conclusion}

This paper analyzes the determinants of incumbent retail prices for fixed-line services across the European Union in the post-liberalization period 1998-2002. The retail prices are determined by regulatory policy and cost factors. Liberalization of fixed-line telephony and regulation, such as, implementation of carrier pre-selection (CPS) and number portability had negative impact on residential prices. In the regression of the usage basket, the regulation decreased average price levels across the EU in the years $1998-2002$ by about $8.2 \%$. Hence, there is a great monetary loss caused by the delay in implementing regulation. Furthermore, a 1\% decrease in termination charges on the incumbent network has led to a $0.17 \%$ decrease in the basket cost.

In the pricing regression for local and national calls interconnection charges are significant only in the estimation of national peak prices. The estimation results suggest that a $1 \%$ decrease in single transit interconnection charges on the incumbent network have led to a $0.31 \%$ decrease in incumbent national prices at peak times, as calculated for the average prices in the EU in 2002. Local interconnection charges seem to have no significant impact on incumbent retail prices for local calls. These results may indicate that incumbent operators are able to retain significant market power in all three markets. Decreases in competitors' marginal costs make the incumbent decrease retail prices at a much lower rate. 


\section{Bibliography}

Bauer, J.M., 2003. "Impact of license fees on the prices of mobile voice service." Telecommunications Policy, 27, 5-6, pp.417-434.

Berg, S. and L.H. Gutierrez, 2000. "Telecommunications liberalization and regulatory governance: Lessons from Latin America", Telecommunications Policy, 24, pp.865-884.

Boylaud, O. and G. Nicoletti, 2000. "Regulation, Market Structure and Performance in Telecommunications", Economics Department Working Paper, No. 237, OECD.

Edwards, G.E. and L. Waverman, 2006. "The Effects of Public Ownership and Regulatory Independence on Regulatory Outcomes: A Study of Interconnect Rates in EU Telecommunications." Journal of Regulatory Economics, 29(1), pp.23-67.

European Commission, 1992. "Towards cost orientation and the adjustment of pricing structures - Telecommunications tariffs in the Community: Communication from the Commission." Brussels, European Commission.

European Commission, 1997a. "Commission recommendation on interconnection in a liberalised telecommunications market." Brussels, European Commission.

European Commission, 1997b. "Directive 97/33/EC of the European Parliament and of the Council of 30 June 1997 on interconnection in Telecommunications with regard to ensuring universal service and interoperability through application of the principles of Open Network Provision (ONP).” Brussels, European Commission.

European Commission, 1997c. "Communication to the Council, the European Parliament, the Economic and Social Committee and the Committee of the Regions on the implementation of the telecommunications regulatory package.” Brussels, European Commission.

European Commission, 1998. "Fourth Report on the Implementation of the Telecommunications Regulatory Package.” Brussels, European Commission. 
European Commission, 1999a. "Status Report on European Union Electronic Communications Policy." Brussels, European Commission.

European Commission, 1999b. "Explanatory Note on Determination of Organisations with SMP for implementation of the ONP Directives." Brussels, European Commission.

European Commission, 2004. "Tenth Report on the Implementation of the Telecommunications Regulatory Package.” Brussels, European Commission.

Fink, C., Mattoo, A. and R. Rathindran, 2002. "Liberalizing Basic Telecommunications: The Asian Experience", HWWA Discussion Paper, No. 163. HWWA-Institut fr Wirtschaftsforschung.

Gruber, H. and F. Verboven, 2001. "The Diffusion of Mobile Telecommunication Services in the European Union", European Economic Review, 45(3), pp.577-588.

Grzybowski, L. 2005. "Regulation of Mobile Telephony across the European Union: An Empirical Analysis", Journal of Regulatory Economics, 28(1), pp.47-67.

ITU, 2002. "Trends in Telecommunication Reform 2002", Geneva.

Li, W., Xu, C.L., (2000) "Liberalization and Performance in the Telecommunications Sector around the World", mimeo, The World Bank.

OECD, 2000. "Telecommunications Basket definitions as of June 2000".

Ros, A.J. 2003. "The Impact of the Regulatory Process and Price Cap Regulation in Latin American Telecommunications Markets', The Review of Network Economics, 2, pp.270286.

Teligen, 1999a. "Report on Telecoms Tariff Data as of January 1998".

Teligen, 1999b. "Report on Telecoms Tariff Data as of January 1999", June.

Teligen, 2000a. "Report on Telecoms Tariff Data as of January 2000". 
Teligen, 2000b. "OECD Telecommunication Basket Definitions".

Teligen, 2001. "Report on Telecoms Tariff Data as of December 2000".

Teligen, 2003. "Report on Telecoms Tariff Data as of December 2002".

Wallsten, S.J. 2001. "An Empirical Analysis of Competition, Privatization, and Regulation in Africa and Latin America", Journal of Industrial Economics, 49(1), pp.1-19.

Wallsten, S.J. 2003. "Of Carts and Horses: Regulation and Privatization in Telecommunications" Journal of Policy Reform, 6(4). 


\section{Appendix}

Table 1: Source of data

\begin{tabular}{|l|l|}
\hline \hline Variables & Source \\
\hline \hline Price of fixed-line services (Fixbill) in US\$ PPP & based on Teligen reports \\
\hline $\begin{array}{l}\text { Price for local peak (Plocp), off-peak (Ploco), national peak (Pnatp) } \\
\text { off-peak (Pnato) calls of 5 min duration in Euro }\end{array}$ & Teligen reports \\
\hline Dummy for liberalization of fixed telephony (Libera) & ETO \& EU reports \\
\hline $\begin{array}{l}\text { Dummy for implementation of number } \\
\text { portability in fixed-line (Portab) }\end{array}$ & ETO \& EU reports \\
\hline $\begin{array}{l}\text { Dummy for implementation of carrier pre-selection } \\
\text { for national calls (CPS) }\end{array}$ & EU reports \\
\hline Dummy for presence of unbundled local loops (ULL) & EU reports \\
\hline $\begin{array}{l}\text { Hourly labor compensation costs in industry } \\
\text { in US\$ PPP (Labor) }\end{array}$ & US Department of Labor \\
\hline $10-$ year government bond yield (Bond) & Eurostat \& OECD \\
\hline $\begin{array}{l}\text { Termination charges for a call of } 5 \text { minute duration: } \\
\text { local (Iloc), single transit (Isin) and double transit (Idou) in cents }\end{array}$ & EU reports \\
\hline GDP per capita in \$US PPP as a logarithm (GDP) & ITU database \\
\hline \hline
\end{tabular}


Table 2: Implementation of main pro-competitive regulatory measures

\begin{tabular}{|l|c|c|c|c|}
\hline \hline Country & ULL & Fixed NP & CPS & Liberalization \\
\hline \hline Austria & 03.2001 & 05.2000 & 03.2000 & 01.1998 \\
\hline Belgium & 01.2001 & 05.2000 & 01.2000 & 01.1998 \\
\hline Denmark & 07.1998 & 10.1999 & 01.1999 & 07.1996 \\
\hline Finland & 06.1997 & 06.1997 & 01.1994 & 1994 \\
\hline France & 01.2001 & 01.2000 & 01.2000 & 01.1998 \\
\hline Germany & 01.1998 & 01.1998 & 01.1998 & 01.1998 \\
\hline Greece & 02.2001 & 01.2003 & 01.2003 & 01.2001 \\
\hline Ireland & 12.2000 & 01.2000 & 01.2000 & 12.1998 \\
\hline Italy & 04.1998 & 06.2000 & 07.2000 & 01.1998 \\
\hline Luxembourg & 01.2001 & 07.2000 & 07.2001 & 07.1998 \\
\hline Netherlands & 05.2001 & 01.1999 & 01.2000 & 01.1998 \\
\hline Portugal & 12.2000 & 06.2001 & 07.2000 & 01.2000 \\
\hline Spain & 01.2001 & 07.2000 & 02.2000 & 12.1998 \\
\hline Sweden & 03.2000 & 07.1999 & 09.1999 & 1993 \\
\hline UK & 08.2000 & 06.1997 & 01.2000 & 1996 \\
\hline
\end{tabular}

Source: www.analysys.com and reports on the Implementation of the Telecommunications Regulatory Package by the European Commission and ETO. 
Table 3: Simple Statistics

\begin{tabular}{|c|r|r|r|r|}
\hline \hline Variable & Mean & Std & Min & Max \\
\hline \hline Fixbill & 68.30 & 22.49 & 37.34 & 133.12 \\
\hline Plocp & 0.18 & 0.06 & 0.08 & 0.38 \\
\hline Ploco & 0.11 & 0.03 & 0.05 & 0.32 \\
\hline Pnatp & 0.57 & 0.35 & 0.13 & 1.46 \\
\hline Pnato & 0.36 & 0.28 & 0.08 & 1.46 \\
\hline Libera & 0.76 & 0.42 & 0.00 & 1.00 \\
\hline Portab & 0.45 & 0.50 & 0.00 & 1.00 \\
\hline CPS & 0.40 & 0.49 & 0.00 & 1.00 \\
\hline ULL & 0.37 & 0.48 & 0.00 & 1.00 \\
\hline Iloc & 2.16 & 1.56 & 0.96 & 12.68 \\
\hline Isin & 2.98 & 1.86 & 1.45 & 12.68 \\
\hline Idou & 4.52 & 3.27 & 1.71 & 21.33 \\
\hline Labor & 19.20 & 5.56 & 6.41 & 30.80 \\
\hline Bonds & 5.37 & 0.87 & 4.50 & 9.90 \\
\hline GDP & 10.12 & 0.22 & 9.62 & 10.79 \\
\hline \hline
\end{tabular}

Table 4: Correlation Coefficients

\begin{tabular}{|c||r|r|r|r|r|r|r|r|r|r|r|c|}
\hline \hline & Fbill & Plocp & Ploco & Pnatp & Pnato & Libe & Port & CPS & ULL & Iloc & Isin & Idou \\
\hline \hline Fixbill & 1.00 & & & & & & & & & & & \\
\hline Plocp & -0.08 & 1.00 & & & & & & & & & & \\
\hline Ploco & 0.24 & 0.42 & 1.00 & & & & & & & & & \\
\hline Pnatp & 0.85 & -0.01 & 0.20 & 1.00 & & & & & & & & \\
\hline Pnato & 0.92 & -0.26 & 0.08 & 0.86 & 1.00 & & & & & & & \\
\hline Libera & -0.64 & 0.09 & -0.17 & -0.62 & -0.66 & 1.00 & & & & & & \\
\hline Portab & -0.50 & 0.05 & -0.24 & -0.45 & -0.45 & 0.51 & 1.00 & & & & & \\
\hline CPS & -0.41 & -0.00 & -0.15 & -0.38 & -0.36 & 0.45 & 0.73 & 1.00 & & & & \\
\hline ULL & -0.35 & -0.15 & -0.09 & -0.30 & -0.29 & 0.43 & 0.57 & 0.66 & 1.00 & & & \\
\hline Iloc & 0.36 & 0.24 & 0.29 & 0.39 & 0.28 & -0.49 & -0.37 & -0.32 & -0.27 & 1.00 & & \\
\hline Isin & 0.47 & 0.12 & 0.18 & 0.47 & 0.37 & -0.49 & -0.42 & -0.32 & -0.29 & 0.86 & 1.00 & \\
\hline Idou & 0.57 & -0.05 & 0.10 & 0.53 & 0.48 & -0.49 & -0.32 & -0.25 & -0.20 & 0.67 & 0.90 & 1.00 \\
\hline \hline
\end{tabular}


Table 5: Fixed effects estimation - basket regression

\begin{tabular}{|c||r|r|r||r|r|r||r|r|r|}
\hline \hline & OLS I & & & OLS II & & & 2SLS & & \\
\hline \hline & Est. & t & sign. & Est. & t & sign. & Est. & t & sign. \\
\hline \hline Austria & -2.15 & -0.33 & 0.74 & 2.53 & 0.58 & 0.56 & -0.29 & -0.06 & 0.95 \\
\hline Belgium & -20.34 & -2.44 & 0.01 & -12.80 & -2.89 & 0.01 & -12.43 & -2.68 & 0.01 \\
\hline Denmark & -23.18 & -4.19 & 0.01 & -23.50 & -5.83 & 0.01 & -23.44 & -5.56 & 0.01 \\
\hline Finland & -23.21 & -3.47 & 0.01 & -20.42 & -4.56 & 0.01 & -24.65 & -4.28 & 0.01 \\
\hline France & -8.03 & -1.84 & 0.07 & -7.62 & -1.90 & 0.06 & -8.38 & -1.98 & 0.05 \\
\hline Germany & -23.66 & -2.44 & 0.01 & -17.00 & -3.67 & 0.01 & -16.03 & -3.27 & 0.01 \\
\hline Greece & 14.21 & 1.36 & 0.17 & 26.85 & 5.25 & 0.01 & 23.13 & 3.79 & 0.01 \\
\hline Ireland & 5.47 & 0.78 & 0.43 & 1.22 & 0.28 & 0.78 & -1.86 & -0.36 & 0.72 \\
\hline Italy & 0.83 & 0.15 & 0.87 & 5.39 & 1.36 & 0.18 & 4.60 & 1.10 & 0.27 \\
\hline Luxebourg & -19.90 & -1.30 & 0.19 & -28.80 & -5.77 & 0.01 & -35.62 & -4.74 & 0.01 \\
\hline Netherlands & -27.67 & -4.41 & 0.01 & -23.67 & -5.58 & 0.01 & -24.37 & -5.45 & 0.01 \\
\hline Portugal & 45.89 & 4.58 & 0.01 & 49.13 & 7.82 & 0.01 & 41.06 & 4.48 & 0.01 \\
\hline Spain & 10.61 & 1.51 & 0.13 & 16.64 & 3.82 & 0.01 & 13.44 & 2.58 & 0.01 \\
\hline Sweden & -29.53 & -6.11 & 0.01 & -26.15 & -6.59 & 0.01 & -27.26 & -6.43 & 0.01 \\
\hline Intercept & 244.79 & 1.00 & 0.31 & 28.12 & 2.67 & 0.01 & 35.95 & 2.85 & 0.01 \\
\hline \hline Libera & -8.15 & -2.98 & 0.01 & -7.40 & -3.02 & 0.01 & -6.55 & -2.48 & 0.01 \\
\hline Portab & -1.06 & -0.35 & 0.72 & & & & & & \\
\hline CPS & -4.58 & -1.35 & 0.18 & & & & & & \\
\hline ULL & 0.84 & 0.27 & 0.79 & & & & & & \\
\hline Access & 5.912 & 3.26 & 0.01 & 4.94 & 2.89 & 0.01 & 8.84 & 2.48 & 0.01 \\
\hline Labor & 2.259 & 2.18 & 0.03 & 1.25 & 3.96 & 0.01 & 0.89 & 2.04 & 0.04 \\
\hline Bonds & 5.094 & 3.02 & 0.01 & 3.18 & 2.58 & 0.01 & 2.06 & 1.32 & 0.19 \\
\hline GDP & -25.157 & -0.98 & 0.33 & & & & & & \\
\hline Time & 4.013 & 1.57 & 0.12 & & & & & & \\
\hline \hline R-Square & 0.95 & & & 0.94 & & & & & \\
MSE & 38.71 & & & 37.99 & & & & & \\
DFE & 51 & & & 56 & & & 41.54 & & \\
\hline F-Value & 12.64 & & & 27.49 & & & 56 & & \\
Pr > F & 0.01 & & & 0.01 & & & & & \\
\hline Hausman & & & & & & & 1.55 & & \\
Pr $>\chi^{2}$ & & & & & & & 1.00 & & \\
\hline \hline
\end{tabular}


Table 6: Random effects estimation - basket regression

\begin{tabular}{|c||r|r|r||r|r|r||r|r|r|}
\hline \hline & Est. & t & sign. & Est. & t & sign. & Est. & t & sign. \\
\hline \hline Intercept & 467.28 & 3.40 & 0.01 & 431.82 & 3.79 & 0.01 & 375.29 & 3.22 & 0.01 \\
\hline \hline Libera & -7.25 & -2.54 & 0.01 & -7.17 & -2.68 & 0.01 & -7.95 & -2.91 & 0.01 \\
\hline Portab & -3.09 & -1.00 & 0.32 & & & & -6.96 & -3.09 & 0.01 \\
\hline CPS & -7.55 & -2.26 & 0.02 & -7.89 & -3.76 & 0.01 & & & \\
\hline ULL & 2.80 & 0.94 & 0.35 & & & & & & \\
\hline Access & 6.66 & 3.59 & 0.01 & 6.83 & 4.23 & 0.01 & 6.87 & 4.09 & 0.01 \\
\hline Labor & 0.53 & 0.81 & 0.42 & & & & & & \\
\hline Bonds & 3.95 & 2.47 & 0.01 & 2.89 & 2.20 & 0.03 & 2.97 & 2.17 & 0.03 \\
\hline GDP & -43.16 & -2.99 & 0.01 & -37.77 & -3.37 & 0.01 & -32.18 & -2.81 & 0.01 \\
\hline Time & 1.21 & 0.58 & 0.56 & & & & & & \\
\hline \hline R-Square & 0.71 & & & 0.70 & & & 0.68 & & \\
MSE & 44.05 & & & 44.32 & & & 47.03 & & \\
DFE & 65 & & & 69 & & & 69 & & \\
\hline Hausman test & 12.90 & & & 8.89 & & & 11.22 & & \\
$P r>F$ & 0.04 & & & 0.01 & & & 0.01 & & \\
\hline \hline
\end{tabular}


Table 7: Fixed effects estimation - local and national peak and off-peak prices

\begin{tabular}{|c|c|c|c|c|c|c|c|c|c|c|c|c|}
\hline & L.peak & & & L.off & & & N.peak & & & N.off & & \\
\hline & Est. & $\mathrm{t}$ & sign. & Est. & $\mathrm{t}$ & sign. & Est. & $\mathrm{t}$ & sign. & & & \\
\hline AUS & 0.072 & 5.04 & 0.01 & 0.070 & 3.19 & 0.01 & 0.083 & 0.69 & 0.49 & 0.073 & 0.73 & 0.46 \\
\hline B & -0.065 & -4.74 & 0.01 & -0.008 & -0.41 & 0.68 & -0.174 & -1.46 & 0.15 & -0.050 & -0.50 & 0.62 \\
\hline DK & -0.106 & -7.27 & 0.01 & -0.022 & -1.01 & 0.31 & -0.329 & -2.60 & 0.01 & -0.091 & -0.86 & 0.39 \\
\hline FIN & -0.129 & -8.09 & 0.01 & 0.024 & 0.98 & 0.32 & -0.131 & -1.04 & 0.30 & 0.035 & 0.33 & 0.74 \\
\hline $\mathrm{F}$ & -0.120 & -8.79 & 0.01 & 0.012 & 0.59 & 0.55 & -0.115 & -0.97 & 0.33 & 0.053 & 0.54 & 0.59 \\
\hline $\mathrm{D}$ & -0.060 & -4.22 & 0.01 & 0.000 & 0.04 & 0.96 & 0.184 & 1.47 & 0.14 & 0.090 & 0.86 & 0.39 \\
\hline EL & -0.173 & -11.22 & 0.01 & -0.017 & -0.73 & 0.46 & 0.063 & 0.48 & 0.63 & 0.515 & 4.67 & 0.01 \\
\hline IRL & -0.055 & -3.99 & 0.01 & -0.037 & -1.76 & 0.08 & -0.172 & -1.44 & 0.15 & 0.015 & 0.15 & 0.88 \\
\hline I & -0.115 & -7.70 & 0.01 & -0.006 & -0.29 & 0.77 & 0.084 & 0.65 & 0.51 & 0.127 & 1.17 & 0.24 \\
\hline $\mathrm{L}$ & -0.066 & -4.24 & 0.01 & 0.014 & 0.58 & 0.56 & -0.561 & -4.60 & 0.01 & -0.227 & -2.23 & 0.03 \\
\hline $\mathrm{NL}$ & -0.117 & -8.84 & 0.01 & -0.010 & -0.50 & 0.62 & -0.370 & -3.25 & 0.01 & -0.166 & -1.75 & 0.08 \\
\hline $\mathrm{P}$ & -0.139 & -8.91 & 0.01 & 0.010 & 0.44 & 0.66 & -0.083 & -0.60 & 0.54 & 0.336 & 2.89 & 0.00 \\
\hline ESP & -0.162 & -11.09 & 0.01 & -0.017 & -0.77 & 0.44 & 0.268 & 2.12 & 0.03 & 0.260 & 2.45 & 0.01 \\
\hline SWE & -0.126 & -9.45 & 0.01 & -0.019 & -0.96 & 0.33 & -0.394 & -3.43 & 0.01 & -0.139 & -1.45 & 0.15 \\
\hline Cons & 0.299 & 19.82 & 0.01 & 0.141 & 6.08 & 0.01 & 0.797 & 6.57 & 0.01 & 0.474 & 4.65 & 0.01 \\
\hline Acce & -0.006 & -1.43 & 0.15 & -0.006 & -0.84 & 0.40 & 0.059 & 2.61 & 0.01 & 0.009 & 0.52 & 0.60 \\
\hline Libe & -0.010 & -1.30 & 0.19 & -0.014 & -1.24 & 0.22 & -0.232 & -3.61 & 0.01 & -0.206 & -3.82 & 0.01 \\
\hline Port & -0.028 & -3.28 & 0.01 & -0.022 & -1.65 & 0.10 & -0.084 & -1.13 & 0.26 & 0.014 & 0.23 & 0.81 \\
\hline CPS & 0.014 & 1.58 & 0.11 & -0.001 & -0.08 & 0.93 & -0.096 & -1.25 & 0.21 & -0.060 & -0.94 & 0.35 \\
\hline ULL & 0.000 & 0.05 & 0.95 & 0.008 & 0.65 & 0.52 & -0.009 & -0.14 & 0.89 & -0.039 & -0.67 & 0.50 \\
\hline R-Sq & 0.92 & & & 0.48 & & & 0.82 & & & 0.81 & & \\
\hline MSE & 0.0004 & & & 0.0009 & & & 0.029 & & & 0.021 & & \\
\hline DFE & 55 & & & 55 & & & 55 & & & 55 & & \\
\hline $\begin{array}{c}\mathrm{F} \\
\text { sign }\end{array}$ & $\begin{array}{l}44.85 \\
0.001\end{array}$ & & & $\begin{array}{c}2.97 \\
0.001\end{array}$ & & & $\begin{array}{c}8.46 \\
0.001\end{array}$ & & & $\begin{array}{c}7.19 \\
0.001\end{array}$ & & \\
\hline
\end{tabular}

